\title{
Barriers of Persons with Physical Disability over Accessibility and Mobility to Public Buildings in Zambia
}

\author{
Brian Chanda Chiluba ${ }^{1 *}$ and Wana Gift Njapawu ${ }^{1}$ \\ ${ }^{1}$ The University of Zambia, School of Health Sciences, P.O. Box50110, Lusaka.
}

\begin{abstract}
To ensure that there is inclusiveness in the provision of services for PWDs the Zambian government ratified to the UNCRPD by enacting the Zambia PWDs ACT No. 6 of 2012 to precisely look at promoting and protecting the rights of PWDs. Despite this, there has been a lack of implementation of the ACT and specifically about accessibility and mobility of PWDs to public buildings. The aim of this study was to explain barriers to implementation of part five division five of The Zambia PWDs on Accessibility and Mobility to public buildings in Lusaka for PWDs. A qualitative case study approach was utilized with sample of 8 participants who by a method of purposeful and convenient sampling were drawn and using thematic method of analysis. This study found that there is a knowledge gap and reduced general knowledge about the ACT among policy implementers. There is need for awareness among people that own building in Lusaka of the Disability ACT. For the policy makers there is a need for prioritization through national planning, budgeting and various national programs.
\end{abstract}

Keywords: Public buildings; Implementation; Barriers; Accessibility; Disability

\section{Research Background}

According to the Universal Declaration of Human Rights, every human being has rights and fundamental freedoms [1]. Therefore, Persons with Disabilities (PWDs) are entitled to all the rights and fundamental freedoms and also empowered to participate fully in society at equal terms with all others, where there is equalization of opportunities for PWDs by empowering them to live independently and participate fully in all aspects of life with regards to accessibility and mobility in the physical environment, public places, institutions among others. There has been a rise in infrastructure development worldwide recently, where it has been observed that new buildings of different sizes and designs as well as new roads in towns and cities have been developed [2]. Therefore, to fully enjoy life an individual must be able to move around and access these physical structures to carry on with activities of daily living (ADLs) as well as social economical activities.

\footnotetext{
* Corresponding author: Brian C. Chiluba

brian.chiluba@unza.zm

Published online at http://IJDS.ub.ac.id/2019- 1

Copyright $\odot$ 2019PSLD UB Publishing. All Rights Reserved
}

The United Nations General Assembly has long identified "accessibility and mobility" as priorities in measures promoting equalization of opportunities for PWDs. And accessibility refers to provision of flexibility to accommodate each user's needs and preferences while mobility refers to the ability to move freely or be easily moved [1]. When used with reference to PWDs, any place, space, item or service, whether it being physical or virtual, that is easily approached, reached, entered, exited, interacted with as well as understood or otherwise used by persons of varying disabilities, is deemed to be accessible [3]. Among the goals, targets and other commitments shaping the international development agenda, the Millennium Development Goals (MDGs) which are now referred to as Sustainable Development Goals stand out as the definitive measure of social progress to date. And the goals have shaped social policy to focus at both the national and the international levels since 2000 , yet disability was not included in the goals or in their operationalizing targets and indicators.

Consequently, disability has largely been invisible in implementations of the Goals and rarely included or considered in national policies 
or programs related to the Goals, much less in monitoring and evaluation efforts. However, in recent years, there has been some increased recognition of the fact that there would be no development path that would exclude the participation of persons with disabilities in economic, social or political life that can be inclusive, equitable or sustainable [4]. In Zambia just as any other countries infrastructure development has taken center stage and The Ministry of Housing and Infrastructure Development is responsible for overseeing infrastructure development.

About $15 \%$ of the world population has been estimated to be living with disability $[5,6]$. According to United Nations statistics, as of the year 2015 there were over 600 million persons with disabilities throughout the world, 400 million of whom live in developing countries and 80 million in Africa. The number of people with disabilities continues to increase in Africa. WHO reported that there are $81,200,000$ disabled persons in Africa which approximately constitutes about 15 to 20 per cent of the total population. Physical disability is associated with accessibility and mobility as well as movement limitation, the inability to use limbs and the body as a whole to effectively move from one point to another because of paralysis, stiffness, pain and loss of a body part or illness [6]. This leads to impairment in social interactions and devaluation of an individual [7].

In order to integrate several perspectives about the disability sequel, the WHO International Classification of Function, Health and Disability (ICF) provides this opportunity. The ICF is a revised version of the WHO's original International Classification of Impairments, Disabilities and Handicaps (ICIDH) which was endorsed by the WHO Assembly in 2001 (WHO, 2001) following some major changes to the original version. According to the WHO, the ICF is a global framework and common language to describe and classify health and health-related states. In summarizing the ICF, the WHO has chosen a Bio-psychosocial approach to health, functioning, and disability in the new ICF model, to provide "a coherent view of different perspectives of health from a biological, individual and social perspective" [8]. It reflects the interactive relationship between health conditions and the contextual factors, personal and environmental factors.
According to the WHO (2001), Disability is an umbrella term representing the dynamic interaction between the person and the environment. All aspects of a person's life (development, participation and environment) are incorporated into the ICF instead of solely focusing on his or her diagnosis because the diagnosis reveals little about one's functional abilities.

At the heart of addressing exclusion from infrastructure is the principal of Universal Design, the process which ensures that systems are usable by all people of all ages and ability, to the greatest extent possible, without the need for adaptation or specialized design. It requires an engineering approach, developing a comprehensive understanding of the challenges to be addressed, establishing clear objectives to achieve and taking a systematic approach to dealing with them. This requires commitment to Universal Access at every level of the project planning, design, implementation and operation, with the concepts institutionalized in the same way as health and safety [9]. This means that buildings ought to be designed and built in a way that every human being should access them despite of their physical state whether they may be living with a disability or not. The Preamble to the Convention emphasizes the importance of mainstreaming disability issues as an integral part of relevant strategies of sustainable development (UNCRPD). And also during the 2013 World Habitat Day, UN Secretary-General Ban Ki-moon called on the international community to make towns and cities accessible for all persons in society, ensuring inclusive development and participation. The United Nations system is taking concrete steps to making sure that the UN environment is more inclusive of and accessible to persons with disabilities and accessibility is also a key goal and means for successful implementation of the Strategy and Plan of Action of the United Nations. According to an accessibility audit study done in Malaysia of about 15 public institutions, it is reported that many of these lacked inclusion of persons with disabilities in the development of the infrastructure [10].

A study was done in Kumasi-Ghana about wheelchair accessibility to public buildings, the results of this study show that public buildings in the Kumasi metropolis are not wheelchair accessible. An important observation made 
during this study was that there is an intention to improve accessibility when buildings are being constructed or renovated, but there are no laid down guidelines as how to make the buildings accessible for wheelchair users [11].

The construction development in Ethiopia is remarkably growing from time to time as it has been seen by the infrastructural developments. This is as the result of the fast and sustainable growth of the country over the last two decades. Though the development would be so holistic, it has not given proper consideration to the benefits of persons with disabilities. [12].

According to the UN (2016), lack of accessibility and mobility brings about barriers to the inclusion and participation of persons with disabilities in economic and social development in communities, cities and a country as a whole. Furthermore, lack of accessibility contributes greatly to the disadvantages and vulnerable situations faced by persons with disabilities, leading to disproportionate rates of poverty, deprivation and exclusion among PWDs.

Global awareness of disability-inclusive development is increasing. The United Nations
Convention on the Rights of Persons with Disabilities (CRPD) promotes the full integration of persons with disabilities in societies. To date, 174 countries have ratified the CRPD, which carries the force of national law. In recent years, an increasing number of bilateral donors have also developed disability policies to guide their international aid. Similarly, at the national level, the numbers of disability discrimination laws and constitutional provisions have increased significantly. We have different Ministries on behalf of the central government that are responsible for overseeing the policy and seeing to it that there is implementation of the same and also provide checks and balances. Among which are the Ministry of Community Development and Social Services as well as Ministry of Local Government and Housing. And there are also institution established in this regard like the Zambia Agency of Persons with Disabilities which oversee issues to do with disability and not forgetting the Zambia Human Rights Commission well as Non-governmental organizations.

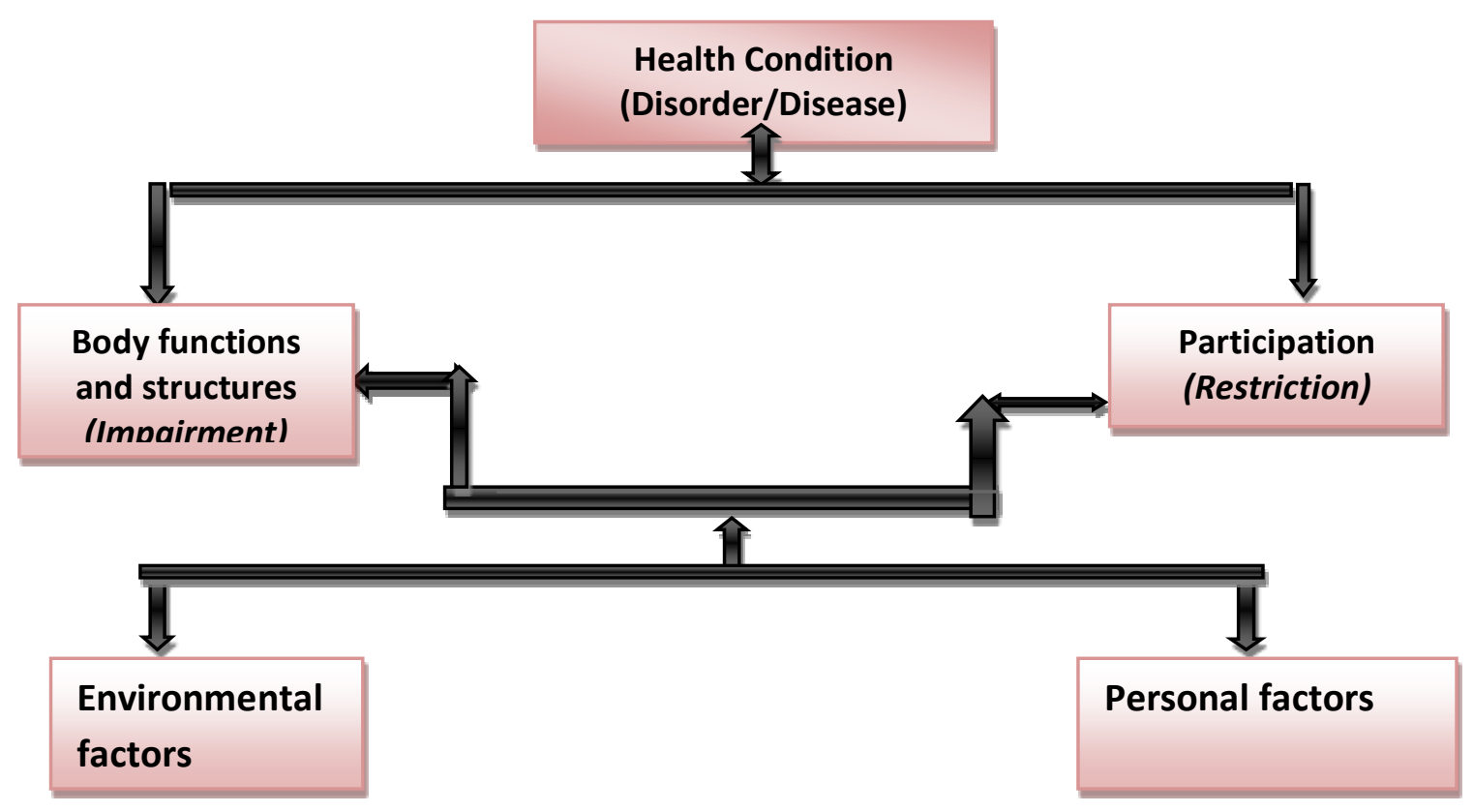

Fig 1. ICF Model of Functioning, Disability and Health Source; ICF (2001) WHO, Geneva, Switzerland 


\section{Method}

\subsection{Design and setting}

This study was a qualitative case study design. This was chosen because qualitative studies bring out a lot of information in order to bring out meaning as well as create an understanding and further explain meaning like in this case where the aim of the study was to explain barriers. The research was conducted in Lusaka- Zambia in the institutions namely; Ministry of Local Government and HousingLusaka City Council, Human Rights Commission, Ministry of Infrastructure Development and Housing and Zambia Agency of Persons with Disability.

\subsection{Study procedures}

Participants were purposefully and conveniently sampled where the researchers selected participants from the institutions mentioned above because they were expected to be able to bring out the relevant information useful to the topic of study and also who had by virtue of their work related to the study topic. After interview with a total of 8 participants there was some data saturation and repetition of views and the data collected was rich enough. Data collection was done by way of an interview guide and an audio recorder and then the data was later transcribed.

\subsection{Analysis}

Thematic analysis was adopted for the study making use of the general inductive approach. Where the researcher generated information and then theories emerged from the data and obtained a conclusion. All the recorded interviews were transcribed and then the transcripts were read several times to identify some codes and the researcher coded by hand out of which themes or categories emerged. Emerging themes (or categories) were developed by studying the transcripts repeatedly and considering possible meanings and how these fitted with developing themes. The researchers finalized the names of the themes and wrote its description with a few quotations from the original text aid put across meaning to the reader.

\section{Results}

The participants were interviewed and guided by a semi-structured questionnaire where in some cases interviews were in a recursive manner meaning that issues were probed as they were mentioned or brought out by the participants. The researcher identified themes and other themes emerged from the views that the participants brought out. And then the findings were presented in a verbatim form as follows:

\subsection{General knowledge about the Disability Act}

When the participants were asked about their general knowledge and understanding of the Zambia Persons with Disability Act No. 6 of 2012 and why it was enacted in Zambia most of them had an understanding that it is actually an Act of parliament that was enacted to promote and protect the rights of persons with disabilities and furthermore, as domestic legislation that helps Zambia as a part to the International Convention on the rights of persons with disabilities to provide within the law as well as to facilitate their full and effective participation in society as well as their full enjoyment of human rights and freedoms just as any human despite them being physically challenged. For instance, one of the participants had this to say in response to the question: -

"It is an Act of parliament, eeh that was passed in 2012 by the national assembly or parliament to promote and protect the rights of persons with disabilities. It is actually a domestic legislation that helps Zambia as a party to the International Convention on the Rights of persons with disabilities to provide within the law the provisions that relate to the promotion and protecting the rights of persons with disabilities. So that those things, $i$ mean the standards that we agree to as a country can be implemented by way of having this law in place. So the implementation, I mean effective implementation of this law will ensure that those rights of persons with disabilities are protected, are being promoted in order to facilitate their full and effective participation in society as well as their full enjoyment of human rights and freedoms on the same level or equal basis with the other persons in Zambia." (Participant 001 male, aged 42 years old).

There were similar and also diverse views in response to the question. Where one participant in conclusion made mention that after this interview and interaction with the researchers there was some reality brought to him about disability issues as most people really 
do not have knowledge about the Act and what is contained in it:-

"For the Act it is good that after we have had this engagement I have gotten to know something about the Act but from our professional point of view there are just certain things that we consider when we are planning for any infrastructure. So it would be good to explore what is in the Act so that we can improve in addition to what we are providing currently because when you are dealing with a statutory instrument we always have to ensure that we have full compliance."(Participant 008 male, aged 38 years old).

\subsection{Understanding of accessibility and mobility to buildings in light of PWDs}

All the participants when asked about their understanding of accessibility and mobility with regards to PWDs as brought out in the Act explained that the part focuses on issues to do with making the physical environment easily accessible and be able to make people with disabilities lead independent lives like any other person despite them being physically challenged. For instance, this one had this to say;

"...it entails access to physical environment...aahhh this is aimed at ensuring that the persons with disabilities have the access to public services and facilities despite having disability, basically it is because in most of these buildings and offices which provide public services and facilities you will find that the buildings are not built in what we call not conformed to the universal design principles when it relates to persons with disabilities" (Participant 002 male, aged 42 years old).

\subsection{Implementation strategies with regards to accessibility and mobility of PWDs}

Most of the participants' views about some of the implementation strategies apparently being put in place as well as which they are personally participating in were the national policy on disability which has outlined programs to be done and who should do what, the Act itself which is an important legislation looking at issues of promoting and protecting the rights of PWDs, ZAPD having a coordinating mechanism and developing standard guidelines that will be followed by anybody who is putting up an infrastructure or a building and also inspectors who go round and inspect any form of building development or infrastructure construction.

"Strategically we have a policy, the disability policy or Act where these issues of accessibility and mobility are mentioned and then all in all we have this law that gives the mandate to the agency so that they go round inspecting all public buildings to see to it that they are accessible and if they are not the same law says that we need to make adjustment orders, where the agency will write to the organization, institution or the owners of that public building to make adjustments so that they are accessible..." (Participant 003 male, aged 50 years old).

And among them one stated how that he personally makes efforts in his capacity to try and contribute to ensuring that there is implementation of the Act on the issues of accessibility and mobility to buildings by PWDs:-

"... well, as an individual. I have rejected certain plans and have advised certain buildings and I wish there were here I could have shown you what I am saying and also at a personal level that is something that I always in-cooperate whenever am doing a design or whenever $i$ am checking any design for approval that is one area that we check." (Participant 008 male, aged 38 years old).

\subsection{Rate of implementation on the Act about accessibility and mobility}

The rate of implementation of the Act on the issues of accessibility and mobility to public buildings by PWDs was described to be generally low by all the participants:-

"I think it is too low to be honest, let us just be honest to ourselves. Yeah, because we are seeing all these buildings, quiet alright we are gona say all these buildings they were there before this law came in or before Zambia signed all these, ratified and whatever but look, there are all these new buildings coming into place and it is like if you tell a new building, they will say fine we are considering the disability we are gona put a ramp, are you sure it is the right ramp that you are putting, is it the right thing that you and Mobility to Public Buildings in Zambia. Indonesian Journal of Disability Studies (IJDS).2019: Vol. 6(1): PP $53-63$. 
are doing? So there are all these things so I think we are still behind. It still goes back to the same I mentioned that I think we need to coordinate these things because an investor or whoever contractor or whoever when they put up a building they will simply say we have put up a ramp but then are you sure somebody on a wheel chair can actually push themselves to pass through there, so you know the only thing they will tell you is we got this building approved by the councils and these specifications from maybe the councils or this building was approved or this plan was approved by the council and what, what what, they will tell you all these things but then the inspector here will say this thing it was not done in a right way because you didn't consider all these dimensions but if the door or stuff. And so I still feel it goes back to the same thing..." (Participant 004 female, aged 32 years old).

\subsection{Factors that influence implementation of the Act about accessibility and mobility}

A lot of factors were brought out by the participants when they were asked what could be some of the factors that lead to low or less implementation of the Act precisely about accessibility and mobility. Most of them said it could be attributed to lack of enforcing penalties, lack of coordinating mechanisms, lack of adequate resources, general negative attitudes and perceptions towards PWDs and also reduced priority. Others brought out were low sensitization about the Act, lack of knowledge about the Act, cost implications when it comes to universal design structures as well as lack of representation by the PWDs themselves and more to all this was less education about the Act:-

"...it is the issue of not having adequate resources to address those challenges, I mean to implementing those policy measures. I think when you look at maybe budget allocation and others you will find that even ZAPD which is supposed to be a coordinating mechanism, they are not so well funded, they are not cutting across the presence the whole country. Talk about lack or resources, they don't have adequate inspectors, they don't have the adequate human and financial resources and so it's the issues of resources but also the other one also is the issue of discrimination which has been going on against persons with disabilities which has been perhaps as result of the negative attitudes, perceptions, our mindset has not been one that embraces you know, or promotes the inclusion of persons with disabilities..." (Participant 001male, aged 42 years old).

\subsection{Key players in implementation of the Act on accessibility and mobility}

Most of the participants when it came to this point mentioned that the key players when it comes to the implementation of the Act precisely on issues of accessibility and mobility of PWDs to public buildings, first and foremost it is the central government because it is the major stakeholder when it comes to providing conditions and also institutions representing PWDs as they are the ones that ought to speak and voice out so that there is general awareness. And they went on further to mention the media, National Construction Council, Zambia Bureau of Standards, Local government, Ministry of Infrastructure and Housing as well as the Engineering Association of Zambia:-

"...the key players here it's the government, for we call them the duty bearers. And if we were to break them down, so the duty bearers are those with obligations to implement and when you look at the policy, when you look at the law it has specifically you know, identified who is supposed to ensure..." (Participant ool male, aged 42 years old)

"....sorry disability organizations play a very critical role. So I don't know we have a number of them across the country. There are different organizations so I feel those also play a critical role, they should be engaged from time to time because at the end of the day there is that saying to say, nothing about us without us. Ifeel they should be brought on board in all this..." (Participant 004 female, aged 32 years old).

\subsection{Root cause of barriers to implementation of accessibility and mobility}

To correct or eliminate a problem thereby preventing it from re-occurring, a root cause analysis maybe employed to help analyze as well as highlight the attributing factors to a specific and Mobility to Public Buildings in Zambia. Indonesian Journal of Disability Studies (IJDS).2019: Vol. 6(1): PP $53-63$. 
problem. The root cause analysis diagram looks at the causes and effect so that the problem does not look vast and insoluble but rather into small and more easily handled chunks. In this case the problem here is barriers to the implementation of the Disability Act on accessibility and mobility and this in this case would be the effect. And so the causes could be attributed to representation of where there is lack of representation of the people with disabilities themselves to be able to contribute in giving ideas as well as bring out their interests. Penalty enforcement is also another cause because there is no seriousness to enforcement of punishment and as such people do not really care because nothing happens to them even when the Act is not followed.

Planning is also one major cause because if there is no proper inclusiveness in the beginning as well as in budget allocations to issues of disability then there will not be any considerations at all. And so correcting things at a later stage may pose or result into financial implications. Furthermore, knowledge about the disability Act also seems to be a major problem as this creates further a knowledge gap among people who are supposed to be in positions that can help foster the rights of PWDs. And implementation strategies are cardinal to ensure that some stringent coordinating mechanisms are put in place so as to ensure proper implementation of the Act on accessibility and mobility of people with physical disability to buildings. And then if key players such as the media, non-governmental organizations, the academia and many others come into play, it would really help in having everyone be well informed thereby aiding in providing an environment that is conducive for all.

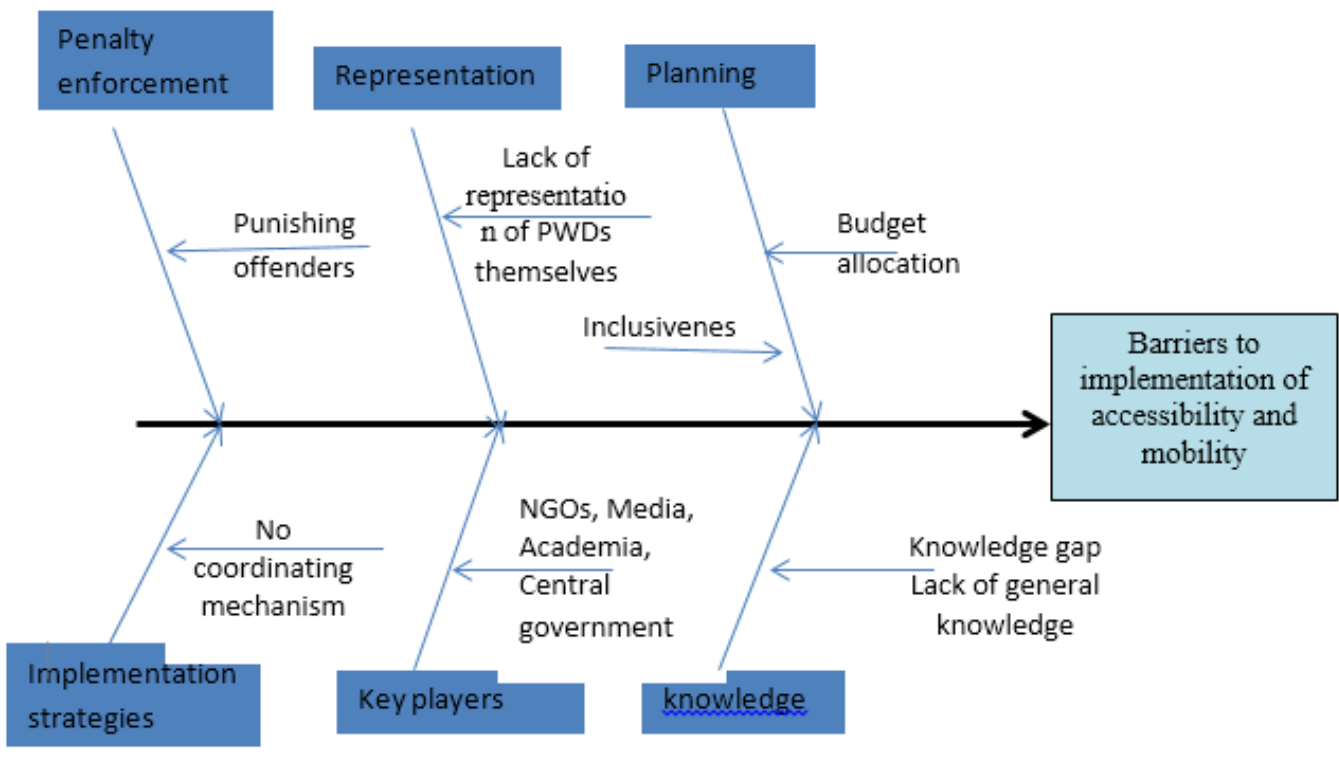

Fig 2. Root cause of barriers to implementation of accessibility and mobility

\section{Discussion}

The discussion focuses on explaining barriers to implementation of the Zambia persons with disabilities Act No. 6 of 2012 part five division five which looks at accessibility and mobility of PWDs to infrastructure. And further discuss the knowledge gap among people who are supposed to be in the forefront in ensuring that there is adherence and later on operationalizing of what the Act brings out and these are administrators (Human resource managers, Directors, Accountants), policy makers (Planners, Engineers, Architects, Development officers) and policy implementers (middle management personnel). And also it looks at their knowledge and understanding precisely of part five of division five of the Act which spells out accessibility and mobility issues and then brings out the implementation strategies and other programs with regards to accessibility and mobility to public buildings for persons with physical disability.

The Zambian government has taken up important strides in line with promoting and 59 
legislations such as the Zambia Persons with Disabilities Act No. 6 of 2012. Despites this important step of domesticating the United Nations Convention on the Rights of Persons with Disability, PWDs still have challenges with regards to mobility and accessibility to public buildings, public institutions, services and facilities [13]. This study reveals some factors that may be attributed to barriers to the implementation of the Act about issues of accessibility and mobility to public buildings by the physically challenged. These includes; reduced levels of knowledge (ignorance) about the Act, lack of prioritization in national planning, budgeting and programs, cost implications, negative attitudes, perceptions and mindset towards disability issues and then lack of PWDs representation. Others are low levels of sensitization and education about the Act, lack of inspectorate and coordinating mechanisms, lack of enforcing penalties to offenders and then lack of attaching seriousness to issues of disability.

The study has shown that there is reduced level of knowledge (ignorance) about the Act in general among people who are supposed to be in positions that ought to foster and promote it as well as be in the forefront of implementing it. This further can be attributed to the fact that people have not attached seriousness to issues to do with PWDs as well as working towards protecting and promoting the rights of PWDs and there are still some negative attitudes, perceptions and mindset towards issues to do with disability. This is also supported by some studies conducted across developing subSaharan countries of which Zambia was included where it has been revealed that people with disabilities face attitudinal barriers including prejudice, stereotypes, and low expectations and these negative attitudes and inaccurate beliefs about disability can result in stigma [14].

Lack of prioritization in national planning, budgeting and programs is also another factor that this study reveals. Owing to the fact that legislations have been put in place but there seem to be lack of implementation because when programs and projects or even developmental projects are coming up, issues to do with disability are left out as they are not considered in the beginning when plans are being developed this can actually be seen from the National census of 2010 in Zambia where it has been observed that data on disability was not carried out or rather included in the program [15]. Furthermore, literature shows that people with disabilities often find that their voices are not included in the processes in which decisions are made therefore their wishes or their needs are predicted by other groups but not by the people themselves that know best what the situation is or what they face [16].

In this study it has been discovered that people who are in influential and key positions of making decisions have not been able to use their privilege to the fullest so as to cause changes and consider PWDs in their planning as well as development programs. Literature reveals that, the 2011 World Report on Disability reports that decision makers often fail to understand the implications of decision making whereas planners and designers also often miss potential for added value to be gained by ensuring access for PWDs [7].

Furthermore, in this study we found that cost implications is also another factor because many buildings were put up many years ago when there was no advocacy or realization of disability issues and so refurbishing and making alterations to these buildings to meet the universal design standard requires a lot of money and as such nothing is done. Literature also reveals this in a study that was done and suggested that new construction arrangements and designs of the environment are more cost effective than retrofitting or overhauling old structures [17].

This study has also shown that there is some evidence of lack of PWDs representation of themselves in key positions starting from planning and budgeting. Projects are planned and put in place minus the input of PWDs themselves to guide and bring out their interests as well as experience and so they are mostly likely to be left out in programs and so they continue to face the challenges with regards to accessibility. In a study by Werner and Scior, it was revealed that involving people with disabilities themselves from the inception of every developmental program is likely to lead to more positive outcomes and make the environment friendly to all. Lack of PWDs representation, low levels of sensitization and education about the Act, lack of inspectorate and 
coordinating mechanisms are other factors that lead to barriers to the implementation of the Act on accessibility and mobility of people with physical challenges to buildings. In another study it was revealed that necessary measures should be taken in order to raise the awareness level of the public and the relevant government organs in connection with the issues of disability and that the Ministry of Higher and Professional Education should integrate the subject matter of accessibility into the syllabus of engineering colleges and polytechnics [17]. Furthermore, lack of enforcing penalties to offenders and lack of attaching seriousness to issues of disability is also another factor that we found. Literature also shows and supports where in a study done by Chilufya (2013) in Zambia, it has been found that among the barriers to the implementation of the Act is inadequate enforcement of the law. People are not punished as such they do not take these matters seriously.

In this study we also found evidence that there is vividly a gap in the general knowledge among administrators, policy makers and indeed policy implementers about The Zambia Persons with Disability Act No. 6 of 2012 and precisely knowledge of division five and part five. Some people may indeed have some knowledge about it while others have only heard or have slight ideas but do not really know what it brings out and what is supposed to be done with regards to accessibility and mobility when it comes to people with physical disability. This may be attributed to the fact that people do not take interest to read about it and it could also be that the legislation has not been made available to people and there may not be high sensitization of disability issues from officers in decision making positions to middle management personnel who are on the ground to be able to implement what the Act spells out. Some studies have shown that if people's attitudes can change to that of embracing as well as realizing the importance of inclusiveness it would help in reducing barriers that PWDs face [18].

However, in this study we have also discovered that despite everything, there are some strides or steps in the right direction as there have been some implementation strategies in line with accessibility and mobility to public buildings for the physically challenged. For instance, there has been an inspectorate department created at Zambia Agency of
Persons with Disabilities which its mandate is to inspect building infrastructures being developed and ensure that they are conformed to universal design principles and if they are not, adjustment orders are given to property owners and developers to make adjustments to the buildings. And also the appointment of focal point personnel in key positions in different government ministries, a move aimed at making sure that there is protection and promotion of the rights of persons with disabilities. This is in line with the UNCRPD that emphasizes and requires that states parties have to designate one or more focal points within government to address matters relating to implementation and to consider establishing a coordination mechanism within government. However, it does not prescribe either the form or the function of these entities.

The UN has reported that many countries have already established or designated disability focal points or coordinating mechanisms. And that the focal points could be a section or a person within a ministry or cluster of ministries, an institution, such as a disability commission, or a particular ministry, such as a ministry for human rights or a ministry for persons with disabilities, or a combination of the three. It goes on to state that even if these bodies or mechanisms already exist, they will need to be revised to oversee the implementation of the Convention and to coordinate efforts among various sectors at the local, regional and national or at federal level. And further that, whatever its designated form be, the focal point should not act in isolation but play a leading role in coordinating the implementation of the Convention and must be equipped with adequate human and financial resources; be established through legislative, administrative or other legal measures; be permanently appointed; and be located at the highest possible level of government [19].

\section{Conclusion}

The results of the study show and indicates that indeed there is need of improvements in the area of implementing what the Act brings out on the issue of accessibility and mobility to public buildings of Lusaka to people with physical disability. It explains the many barriers to the implementation of the Act precisely part five of 
division five among which is a knowledge gap among people in policy making positions and those who are supposed to be implementers of the Act. Furthermore, lack of prioritization in national planning, budgeting and programs, cost implications, negative attitudes, perceptions and mindset towards disability issues and lack of PWDs representation are among the barriers to the implementation on accessibility and mobility of the Act. And this requires a system-wide and integrated approach to be able to overcome these barriers. It requires the setting of coordinating mechanisms that will aim to monitor the standards set and the decisions made as well as plans. Disability organizations, the central government as well as each citizen need to play a critical role to ensure that there is realization. The media should also work to sensitize people both in decision making positions and everyone to be educated about the Act and what it spells out so that there is a change of attitude among implementers and everyone at large. Nongovernmental organizations can play a major role in putting accessibility issues on the social agenda. The academia also has a critical role to play in ensuring that they integrate the subject matter of accessibility into the syllabus of engineering colleges and polytechnics.

\section{Acknowledgements}

This paper is part of the Bachelors of Science in Physiotherapy dissertation requirement by Wana Gift Njapawu. And sincere special thanks to Dr Martha Banda Chalwe and Mr Brian Chanda Chiluba as well as all the members of stuff in the School of Health Sciences, Department of Physiotherapy at The University of Zambia.

\section{References}

United Nations General Assembly (1948). Universal Declaration of Human Rights, 217 A (111).

International Standards Organisation, (2011). International Standards, ISO 21542, Buildingconstruction-Accessibility and usability of the built environment. Geneva: ISO.

UNITED NATIONS, Department of Economic and Social Affairs Division for Social Policy and Development (2013). Accessibility and
Development, Mainstreaming disability in the post-2015 development agenda.

ECA, African Union, African Development Bank Group and United Nations Development Programme (2014). MDG 2014 report: assessing progress in Africa toward the Millennium Development Goals, Addis Ababa.

WHO (2015). Regional Office for Africa, "Disabilities".

WHO development Regional Office for Africa (2015). "Disability and Rehabilitation".

World Health Organisation (WHO), World Bank (WB). (2011). World Disability Report.

World Health Organization (2001). ICIDH-2 International Classification of Functioning and Disability, Geneva

Henry, Shawn Abou-Zahra, Shadi, Brewer, Judy, (2014). "The Role of Accessibility in a Universal Web". Proceeding W4A '14 Proceedings of the 11th Web for All Conference Article No. 17.

Syazwani Abdul Kadir and Mariam Jamaludin, (2012). Users' Satisfaction and Perception on Accessibility of PublicBuildings in Putrajaya: Access Audit Study, Elservier Ltd, Malaysia.

Yarfi, C., Ashigbi, E.Y.K., Nakua, E.K. (2017). 'Wheelchair accessibility to public buildings in the Kumasi metropolis, Ghana', African Journal of Disability 6(0), a341

Yared Gebremeden (2016). Ethiopia, Disability, Accessibility in Sustainable Urban Development. The Ethiopian Herald, All Africa Global Media

Chilufya M.M, (2013). Accessibility of Public Building to Disabled Persons, University of Zambia, School of Law, Zambia.

Division for Social Policy and Development (DSPD), (2016). Toolkit on Disability for Africa-Culture, Beliefs and Disability. UN.

Banda-Chalwe, M., Nitz, J.C. \& De Jonge, D (2013). 'Impact of inaccessible spaces on community participation of people with mobility limitations in Zambia', African Journal of Disability, Art. \#33. and Mobility to Public Buildings in Zambia. Indonesian Journal of Disability Studies (IJDS).2019: Vol. 6(1): PP $53-63$. 
DOI:

British Council (2016). IDEAS, Inclusive Decision-making for Equal and Accountable Societies, UK.

Al-Ghaib, O.A., Andrae, K., Gondwe, R. (2017). Still left behind: Pathways to inclusive education for girls with disabilities. Leonard Cheshire Disability.
Paterson J, (2000). Workers of south India their attitudes and their education. Asia Pacific Disability Rehabilitation Journal, 10(1), 1 - 16.

UN DESA/DSPD (2016). Ecuador High-Level Forum on Disability Accessibility and Inclusive Urban Development, Summary Report of Forum, Quito, Ecuador. 